\title{
Immunomodulatory Potential of Leptadenia arborea in Immune-Challenged Rats
}

\author{
Iman Hassan Abdoon', Bushra Parveen², Bashier Osman', Mona S Mohamed³, Wadah JA Osman ${ }^{3}$, \\ Sayeed Ahmad",*
}

${ }^{1}$ Department of Pharmacology, Faculty of Pharmacy, University of Khartoum, Khartoum, SUDAN.

2Department of Pharmacology and Pharmaceutical Medicine, School of Pharmaceutical Education and Research, Jamia Hamdard, New Delhi, INDIA.

${ }^{3}$ Department of Pharmacognocy, Faculty of Pharmacy, University of Khartoum, SUDAN.

${ }^{4}$ Bioactive Natural Product Laboratory, School of Pharmaceutical Education and Research, Jamia Hamdard, New Delhi, INDIA.

\begin{abstract}
Background: Plant-based remedies play a crucial role as powerful health aid worldwide. In recent years, the usage of complementary and alternative medicines has grown rapidly. The objective of the present study was to evaluate the immunomodulatory effects of methanolic extract of Leptadenia arborea leaves in BCG-immunized rats. Materials and Methods: L. arborea extract suspended in $1 \%$ carboxymethyl cellulose (CMC) was administered in three doses viz 50, 100 and $200 \mathrm{mg} / \mathrm{kg}$, p.o. All animals were challenged with $0.05 \mathrm{ml} \mathrm{BCG}$, sc on day 0 . Levamisole $(18 \mathrm{mg} / \mathrm{kg}$ body weight; p.o.) was used as a positive control group. Results: L. arborea extract exhibited a significant dose- and time-dependent increase in the plasma levels of IFN- $\gamma$ and TGF- $\beta$. On day 14, plant's extract significantly increased TNF- $\alpha$ level at dose $200 \mathrm{mg} / \mathrm{kg}$. Moreover, L. arborea extract elicited an inhibitory effect on IL-10 levels that was significantly observed at dose $200 \mathrm{mg} / \mathrm{kg}$ of the plant extract. LD $_{50}$ value was calculated to be $15.5 \mathrm{~g} / \mathrm{kg}$ body weight and the extract didn't display any behavioral changes or clinical signs after $12 \mathrm{hr}$ of treatment. Conclusion: $L$. arborea methanol extract showed immunostimulatory effects through elevation of IFN- $\gamma$ and thereby activation of cell-mediated immunity.
\end{abstract}

Key words: Leptadenia arborea, Cell-mediated immunity, TH1 cytokines, TH2 cytokines, Immunomodulator.

\section{INTRODUCTION}

The use of herbal medicines over the past decade has increased tremendously across the world both in developing and developed countries including the UK and the rest of Europe, as well as in North America and Australia. ${ }^{1}$ It is estimated that approximately $80 \%$ of the world's populations rely on herbal medicinal products as a primary source of health care, ${ }^{2,3}$ and herbal medicines constitute a central part of the medical system in countries like India and China as a traditional system of medicine, ${ }^{4,5}$ The importance of plant and plant-derived compounds cannot be denied due to the fact that the modern pharmacopeias contain at least $25 \%$ drugs derived from plants and many other synthetic analogs that are isolated from them ${ }^{6,7}$ such as paclitaxel, camptothecin, etoposide, mevastatin and artemisinin. ${ }^{8,9}$ Leptadenia arborea (Asclepiadaceae) is a valuable medicinal plant, widely distributed in tropical Africa and the Arabian Peninsula. In Sudan, it is called "sha'aloub or sho'bait" and is widely spread along the White Nile province and Gash Delta in Eastern Sudan. ${ }^{10,11}$ Leptadenia species have a rich phytoconstituent profile containing beta-amyrin, alpha-amyrin, $\beta$-sitosterol, stigmasterol, campesterol, triterpene alcohol and several flavonoids such as apigenin, kaempferol, luteolin, diosmetin, astragalin and isoquercitrin. ${ }^{12-14}$ Leptadenia arborea is used traditionally in Sudan to treat
Submission Date: 13-06-2019; Revision Date: 04-09-2019; Accepted Date: 12-11-2019

DOI: 10.5530/ijper.54.1.12 Correspondence: Dr. Sayeed Ahmad, Incharge, Bioactive Natural Product Laboratory, School of Pharmaceutical Education and Research, Jamia Hamdard, New Delhi, INDIA. Phone: +919891374647 E-mail: sahmad_jh@yahoo. co.in

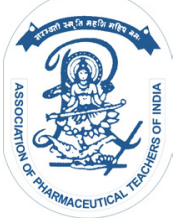

www.ijper.org 
rheumatoid arthritis, gonorrhea, constipation, colic and snake bites. ${ }^{11}$

Plant-derived natural products such as polysaccharides, flavonoids, alkaloids, sesquiterpene lactones and triterpenes have received considerable attention in recent years due to their diverse pharmacological properties such as immunomodulatory, anti-inflammatory, cytotoxic, cancer chemopreventive and anti-HIV. ${ }^{15-19}$ The use of plant products as immunomodulator has a traditional history from the ancient times and the modern characterization techniques have isolated the bioactive constituents of plants that are found to stimulate the immune system. ${ }^{20,21}$ The therapeutic potential of immunomodulatory agents from plant sources and their curative properties have been reported in previous studies. However, the present work was carried out to evaluate the immunomodulatory potential of methanolic extract of $L$. arborea leaves in Bacillus Calmette-Guérin (BCG)immunized rats.

\section{MATERIALS AND METHODS}

\section{Animals and maintenance}

Albino rats (average weight $180 \mathrm{~g}$ ) of either sex were obtained from the animal house of Faculty of Pharmacy, University of Khartoum, Sudan. They were housed in standard plastic cages and maintained under standard laboratory conditions of temperature $\left(25^{\circ} \mathrm{C} \pm 1^{\circ} \mathrm{C}\right)$, light (12 hr light/dark cycle) and controlled humidity. They had free access to standard diet and clean water ad libitum. The experimental protocol was approved by the local Ethics Committee (Ethics Committee for Animal Experimentation, Faculty of Pharmacy - University of Khartoum, Sudan) and the experiments were performed in accordance with Institutional Animal Welfare Guidelines.

\section{Plant collection and extraction}

L. arborea plant was collected from Khartoum state in central Sudan. It was identified and authenticated by the Department of Medicinal and Aromatic Plants at the National Centre for Research, Khartoum, Sudan. Leaves of the plant were air-dried in the shade and then they were pounded into coarse powder. The extraction procedures were carried out at laboratory of medicinal and aromatic plants at National Centre for Research, following the established extraction procedure of plant materials. $100 \mathrm{~g}$ of the powdered plant was macerated in one liter of $80 \%$ methanol at room temperature for $24 \mathrm{hr}$ with occasional shaking. It was then concentrated under reduced pressure, using the rotary vacuum evaporator and dried to a solid mass under air at room tem- perature. The dry extract was stored at $4^{\circ} \mathrm{C}$ until analysis was carried out.

\section{Experimental protocol}

Thirty rats (average body weight $180 \mathrm{~g}$ ) were randomly allocated into five groups $(n=6)$. The extract was suspended in 1\% carboxymethyl cellulose (CMC) (Chemcolloids Ltd. UK). On day 0, all groups were sensitized subcutaneously with $0.05 \mathrm{ml}$ BCG. Group 1 (vehicle control group) received 1\% CMC (50 mg/ $\mathrm{kg}$ body weight; p.o.) whereas group 2 (positive control group) was dosed orally with $18 \mathrm{mg} / \mathrm{kg}$ levamisole (Sigmaaldrich Inc. USA). Group 3, 4 and 5 (plant treated groups) received three doses vir 50, 100 and $200 \mathrm{mg} / \mathrm{kg}$ body weight; p.o. of the extract, respectively. The dosing was continued for a duration of 14 days.

On the $1^{\text {st }}$ day (before challenge), $7^{\text {th }}$ and $14^{\text {th }}$ day, blood was withdrawn from retro-orbital plexus of each animal under mild ether anesthesia (Figure 1). Plasma was separated after centrifugation and stored at $-80^{\circ} \mathrm{C}$ until biochemical analysis.

\section{Measurement of T Helper cell (TH) 1 and T Helper cell (TH) 2 cytokines in plasma}

Plasma levels of tumor necrosis factor- $\alpha$ (TNF- $\alpha$ ) and interferon $\gamma$ (IFN- $\gamma$ ) (TH1 cytokines) in plasma were quantified using rat antibody specific enzyme linked immunosorbent assay (ELISA) kits (Peprotech Company, USA), according to the manufacturer's instructions. Tumor growth factor $\beta 1$ (TGF- $\beta 1$ ) and interleukin-10 (IL-10) (TH2 cytokines) were analysed using rat antibody specific ELISA kits (Bender Medsystem Company/eBioscience, USA), following the manufacturer's protocol.

\section{Acute oral toxicity study}

Methanolic extract of $L$. arborea leaves was tested for acute toxicity studies as per the procedure given in Organization for Economic Cooperation and Development (OECD) guidelines 425 and limit test method was followed. ${ }^{22}$

Albino rats weighing between 120 to $210 \mathrm{~g}$ of either sex were randomly distributed into six groups $(n=8)$. The animals were deprived of food but not water (16-18 h) prior to administration of the plant extract. Five groups of animals were fed with single oral doses of the plant extract (2, 4, 8, 11 and $13 \mathrm{~g} / \mathrm{kg} /$ bodyweight), suspended in $1 \% \mathrm{CMC}$. The $6^{\text {th }}$ group (control group) received $1 \%$ CMC (50 mg/kg body weight; p.o.). Following oral administration of extracts, the animals were closely observed for general and behavioral changes that were recorded systematically at 24,6 and 12 h after the dosing. The visual observations included skin and fur, eyes, 
nose, motor activity, respiration, lacrimation and feces consistency. Further, the animals were observed at 24 and $48 \mathrm{~h}$ after dosing for mortality rate. The number of animals died from each group were recorded and the toxicological effects were assessed based on mortality, which was expressed as $\mathrm{LD}_{50}$ value (the median lethal dose that kills $50 \%$ of animal population). $\mathrm{LD}_{50}$ value was determined by using a computer program SPSSprobit analysis. ${ }^{23}$ The higher the $\mathrm{LD}_{50}$ value, the lower will be the toxicity of the plant extract.

\section{Statistical analysis}

Data were expressed as Mean \pm S.E.M. Levels of difference between all groups were determined by one-way analysis of variance (ANOVA) followed by Dunnett's t-test. $P$-values $\leq 0.05$ were considered as statistically significant.

\section{RESULTS}

\section{L. arborea extract enhanced IFN-Y production in immune challenged rats}

L. arborea extract exhibited dose-dependent increase in IFN- $\gamma$ levels on day $7(p \leq 0.05)$ and day $14(p \leq 0.05)$ with a highly significant increase seen at dose $200 \mathrm{mg} /$ $\mathrm{kg}(p \leq 0.01)$. Moreover, the effect of $L$. arborea extract on the time course of IFN- $\gamma$ levels revealed a significant time-dependent increase in IFN- $\gamma$ levels at a dose of $200 \mathrm{mg} / \mathrm{kg}$ of the plant extract $(p \leq 0.01)$. Interestingly, the increased IFN- $\gamma$ levels at $200 \mathrm{mg} / \mathrm{kg}$ dose was somewhat similar to that of the positive control group, i.e. levamisole (Figure 2 and Figure 3).

\section{$L$. arborea extract induced TGF- $\beta$ production in immune-challenged rats}

With regard to TGF- $\beta, L$. arborea extract exerted a significant dose and time-dependent increase in the plasma levels of TGF- $\beta$ on $7^{\text {th }}$ and $14^{\text {th }}$ day $(p \leq 0.05)$, as compared with the control group. Further, TGF- $\beta$ level at the dose of $200 \mathrm{mg} / \mathrm{kg}$ was significantly higher than that of positive control group (levamisole) on $7^{\text {th }}$ and $14^{\text {th }}$ day $(p \leq 0.05)$ (Figure 2 and Figure 3).

\section{$L$. arborea extract attenuated IL-10 level in immune-challenged rats}

The immunomodulatory effects of $L$. arborea were further assessed by measuring the plasma levels of IL-10 after oral administration of plant extract. L. arborea extract exhibited a significant decrease at a dose of 200 $\mathrm{mg} / \mathrm{kg}$ on $7^{\text {th }}$ and $14^{\text {th }}$ day after treatment, indicating an inhibitory effect of $L$. arborea extract on IL-10 levels (Figure 2 and Figure 3).

\section{L. arborea extract enhanced TNF-a production in immune-challenged rats}

L. arborea extract showed an increasing trend in the TNF- $\alpha$ levels at doses- 50 and $100 \mathrm{mg} / \mathrm{kg}$ on day $14^{\text {th }}$, however, with a dose of $200 \mathrm{mg} / \mathrm{kg}$, a significant increase in TNF- $\alpha$ level was observed on day 14 ( $p \leq$ 0.05) (Figure 2 and Figure 3).

\section{Acute oral toxicity study}

The lethality was measured $24 \mathrm{hr}$ after treatment with $L$. arborea extract; and then $\mathrm{LD}_{50}$ value was calculated to be $15.5 \mathrm{~g} / \mathrm{kg}$ body weight, using probit analysis (Table 1). Furthermore, the behavioral patterns of rats including changes in skin and fur, eyes, nose, motor activity, respiration, lacrimation and feces consistency, were observed upto $12 \mathrm{hr}$ after administration of the treatment. $L$. arborea extract did not display any behavioral changes or general signs in treated and untreated rats after plant administration (Table 2).

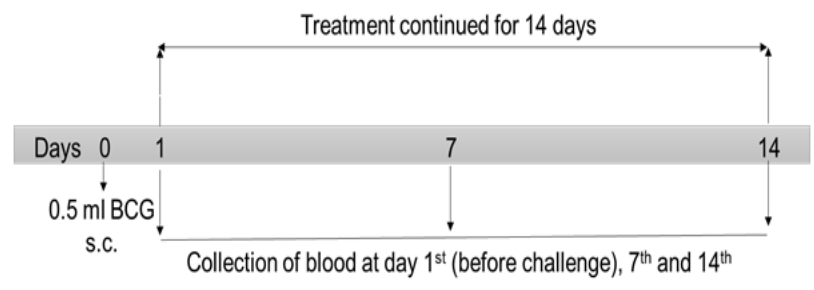

Figure 1: Experimental protocol.

\begin{tabular}{|c|c|c|c|c|c|c|}
\hline Groups & Dose $(\mathrm{g} / \mathrm{kg})$ & Log dose & Total N & \%Dead & Probit & $\operatorname{LD}_{50}(\mathrm{~g})$ \\
\hline Group2 & 2 & 0.30103 & 8 & 0 & 0 & \multirow{6}{*}{15.5} \\
\hline Group3 & 4 & 0.60206 & 8 & 12.5 & 3.82 & \\
\hline Group4 & 8 & 0.90309 & 8 & 12.5 & 3.82 & \\
\hline Group5 & 11 & 1.041393 & 8 & 25 & 4.33 & \\
\hline Group6 & 13 & 1.113943 & 8 & 25 & 4.33 & \\
\hline Group1 (control) & 0 & 0 & 8 & 0 & 0 & \\
\hline
\end{tabular}


Table 2: General appearance and behavioral observations for rats after Leptadenia arborea administration.

\begin{tabular}{|c|c|c|c|c|c|c|c|c|}
\hline \multirow{2}{*}{ Observations } & \multicolumn{4}{|c|}{ Control group } & \multicolumn{4}{c|}{ Treated groups } \\
\cline { 2 - 9 } & $\mathbf{2} \mathbf{~ h r s ~}$ & $\mathbf{4} \mathbf{~ h r s}$ & $\mathbf{6} \mathbf{~ h r s}$ & $\mathbf{1 2} \mathbf{~ h r s}$ & $\mathbf{2} \mathbf{~ h r s}$ & $\mathbf{4} \mathbf{~ h r s}$ & $\mathbf{6} \mathbf{~ h r s}$ & $\mathbf{1 2} \mathbf{~ h r s}$ \\
\hline Skin/fur & normal & normal & normal & normal & normal & normal & normal & normal \\
\hline Eyes & normal & normal & normal & normal & normal & normal & normal & normal \\
\hline Nose & normal & normal & normal & normal & normal & normal & normal & normal \\
\hline Respiration & normal & normal & normal & normal & normal & normal & normal & normal \\
\hline Lacrimation & normal & normal & normal & normal & normal & normal & normal & normal \\
\hline Motor activity & normal & normal & normal & normal & normal & normal & normal & normal \\
\hline Feces consistency & normal & normal & normal & normal & normal & normal & normal & normal \\
\hline
\end{tabular}

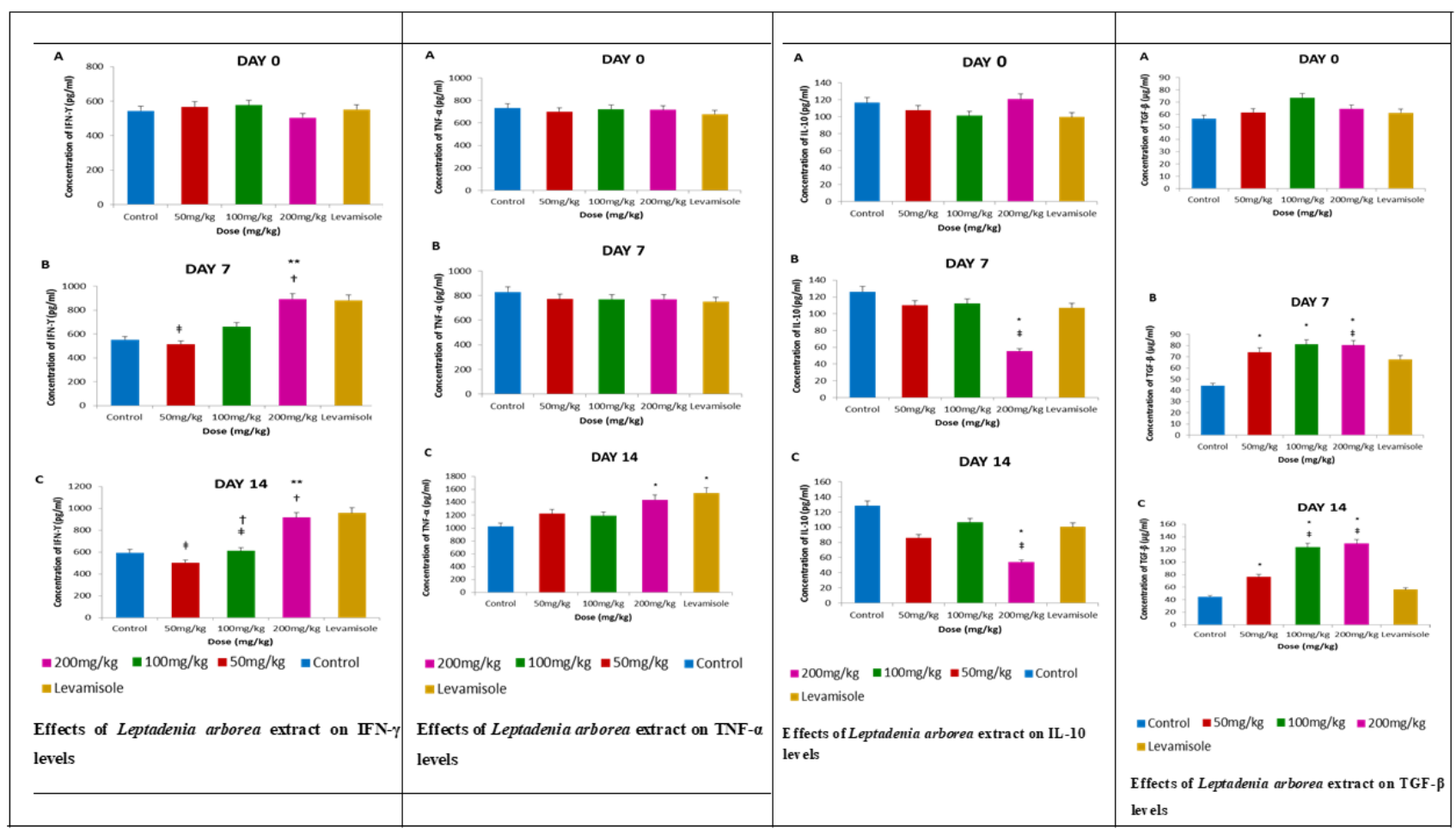

Figure 2: Dose-dependent effects of Leptadenia arborea extract on IFN- $y$, TNF $_{-\alpha}$, IL-10 and TGF ${ }_{-\beta}$ levels. *Rats were treated with L. arborea extract $(50,100$ and $200 \mathrm{mg} / \mathrm{kg})$, levamisole $(18 \mathrm{mg} / \mathrm{kg})$ or vehicle for 14 days. Data were presented as mean \pm SEM. *, $p \leq 0.05$ versus control. $¥, p \leq 0.05$ versus levamisole.

\section{DISCUSSION}

The history of drug discovery revealed that plants are an important source of novel pharmacologically active compounds and the plant-based or derived remedies play a crucial role in the medical system worldwide. ${ }^{8} \mathrm{~A}$ burgeoning interest in medicinal plants encourages large scale pharmacological screening of herbs and search for new leads derived from plant origin for development of potent and safe agents. ${ }^{4,24}$ In the last few years, considerable attention has been paid to plant-derived natural products as potential immunomodulatory agents. ${ }^{25}$

As immunomodulators, medicinal plants may act by stimulating both specific and Non-specific immunity. Phytochemicals such as flavonoids, polysaccharides, lac- tones, alkaloids, diterpenoids and glycosides have been reported to be responsible for the immunomodulating properties of the plants. ${ }^{26}$ Plant-based immunomodulators can provide an effective and safe alternative to conventional chemotherapy for a variety of immune disorders including cancer, immunodeficiency, autoimmune diseases and various infectious and inflammatory conditions. ${ }^{27,28}$

This study aimed to determine the immunomodulatory effects of $L$. arborea that has been used traditionally to treat various infectious diseases in Sudan. Four cytokines (IFN- $\gamma$, TNF- $\alpha$, IL-10 and TGF- $\beta$ ) were quantified by ELISA. Cytokines have been demonstrated to play a crucial role in differentiation of $\mathrm{TH}$ cell into Th1 and 


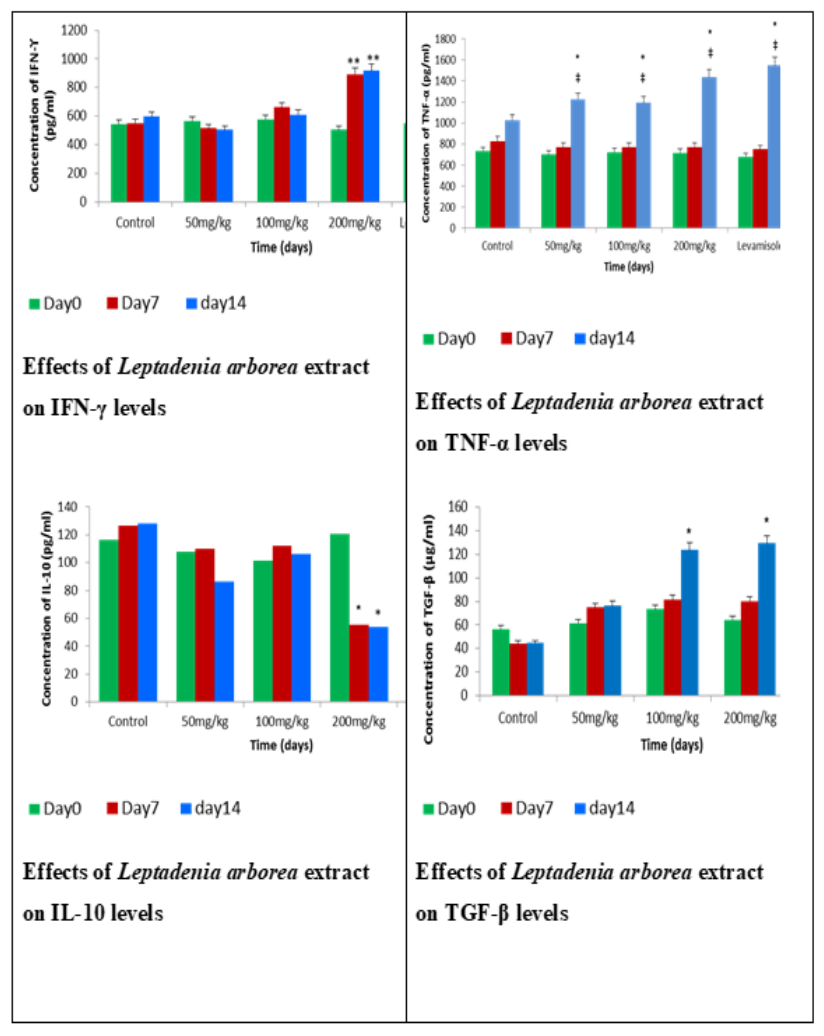

Figure 3: Time-dependent effects of Leptadenia arborea extract on IFN- $\gamma$, TNF- $a$, IL-10 and TGF- $\beta$ levels. ${ }^{*}$ Rats were treated with $L$. arborea extract $(50,100$ and $200 \mathrm{mg} / \mathrm{kg}$ ), levamisole $(18 \mathrm{mg} / \mathrm{kg})$ or vehicle for 14 days. Data were presented as mean \pm SEM. * $p \leq 0.05$ versus day 0

Th2. These cytokines were chosen due to their critical role in innate and adaptive immunity that could be either cell-mediated or antibody-mediated immunity. Indeed, the reciprocal control mechanisms of Th1 and Th2 differentiation, using Th1 cytokines (IL-2, IL-12, IFN- $\gamma$ and TNF- $\alpha$ ) and Th2 cytokines (IL-4, IL-5, IL-10 and TGF- $\beta$ ), is critical for directing the immune response toward cell-mediated or humoral-mediated responses. Thus, any factors that can interfere with Th1/Th2 axis might affect the outcome of the immune response. ${ }^{29,30}$ This study demonstrated that the $L$. arborea methanolic extract exhibited a significant dose- and time-dependent increase in TGF- $\beta$ level which is an indicative marker for the anti-inflammatory activity of the plant extract. These findings are in line with a previous study where ethanolic extract of $L$. arborea showed anti-inflammatory activity against carrageenan-induced paw edema in rats. ${ }^{31}$ Anti-inflammatory activity of this plant is attributed to its enriched phytochemical profile including flavonoids, beta-amyrin and alpha-amyrin, as also reported in previous studies. ${ }^{32,33}$ Furthermore, L. arborea extract elicited a dose- and time-dependent increase on IFN- $\gamma$ and TNF- $\alpha$ levels while exhibited an inhibitory effect on IL-10 production. Accordingly, the plant extract provoked stimulatory effect on cell-mediated immunity through induction of TNF- $\alpha$ and IFN- $\gamma$ production; and in contrary inhibition of IL-10 level. On the basis of these findings, $L$. arborea could be recommended as a good candidate for treatment of various infectious diseases and support its traditional claim as anti-rheumatic agent. ${ }^{11}$ Several previous reports have found immunopotentiating activity in Leptadenia species which are not clearly distinguished from $L$. arborea. ${ }^{34}$ A previous study demonstrated that $L$. reticulata produces a stimulatory effect on the immune system, ${ }^{13}$ and potentiates antibody titer values and percentage neutrophil adhesion to nylon fibers as well as phagocytosis in carbon clearance assay. Therefore, L. reticulata may play an important role in reducing the risk of developing immunodeficiency disorders. ${ }^{35}$ Moreover, another in vitro study has confirmed that the aqueous extract of $L$. reticulata alleviates the immunosuppressive conditions induced by the immunotoxicant, chromate. ${ }^{36}$ The immunomodulatory activity of $L$. heterophylla may be attributed to the presence of a mixture of sterols (campesterol, stigmasterol and $\beta$-sitosterol), triterpene alcohol and several flavonoids that are previously documented as plant-derived immunomodulatory products. ${ }^{26,37}$

In the present study, the lethal dose $\left(\mathrm{LD}_{50}=15.5 \mathrm{~g} / \mathrm{kg}\right)$ of methanolic extract of $L$. arborea strongly suggests the low oral toxicity of the extract, as $\mathrm{LD}_{50}$ value greater than $5000 \mathrm{mg} / \mathrm{kg}$ by the oral route is regarded as being safe or of low toxicity. ${ }^{38}$ Additionally, according to OECD guidelines for acute oral toxicity, ${ }^{39}$ the substances with $\mathrm{LD}_{50}$ dose of $2000 \mathrm{mg} / \mathrm{kg}$ and above are categorized as non-toxic and safe compounds. Moreover, absence of any behavioral changes after administration of different oral doses of $L$. arborea supported the safety of this plant extract.

\section{CONCLUSION}

To conclude, we show that treatment with methanolic extract of $L$ arborea in immune challenged rats for a duration of 14 days exhibits immunostimulatory effects as demonstrated by higher plasma levels of IFN- $\gamma$ and TGF- $\beta$ and lower levels of IL-10. Further, our results suggests low oral toxicity of the extract as evident by $\mathrm{LD}_{50}$ value greater than $500 \mathrm{mg} / \mathrm{kg}$. The absence of any sign of behavioral change after administration of $L$. arborea extract at different oral doses further supported the safety of this plant extract. Therefore, these safety findings may explain and support the wide traditional use of L. arborea in Sudan for therapeutic management of several ailments. 


\section{Data availability}

The data used to support the findings of this study are included within the methodology section of the article.

\section{ACKNOWLEDGEMENT}

Authors are thankful to Faculty of Pharmacy, University of Khartoum for providing necessary facilities and Dr. Sayeed Ahmad, SPER, Jamia Hamdard, New Delhi for his scientific inputs.

\section{CONFLICT OF INTEREST}

The authors declare no conflict of interest.

\section{ABBREVIATIONS}

ANOVA: Analysis of Variance; BCG: Bacillus CalmetteGuérin; CMC: Carboxy Methyl Cellulose; ELISA: Enzyme linked immunosorbent assay; HIV: Human Immunodeficiency Virus; IFN- $\gamma$ : Interferon $\gamma$; IL-10: Interleukin 10; $\mathbf{L D}_{50}$ : Lethal dose 50; OECD: Organization for Economic Cooperation and Development; TGF $\beta$ : Tumor growth factor $\beta$; TH1: T Helper cell 1; TH2: $T$ Helper cell 2; TNF- $\alpha$ : Tumor necrosis factor- $\alpha$.

\section{REFERENCES}

1. Ekor M. The growing use of herbal medicines: issues relating to adverse reactions and challenges in monitoring safety. Front Pharmacol. 2014;4:177.

2. Nissen N. Practitioners of Western herbal medicine and their practice in the UK: Beginning to sketch the profession. Complement Ther Clin Pract. 2010;16(4):181-6.

3. Barnes PM, Bloom B, Nahin RL. Complementary and alternative medicine use among adults and children: United States. Natl Health Stat Report. 2008;12:1-23.

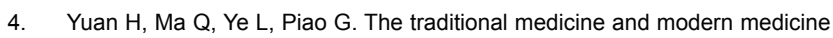
from natural products. Molecules. 2016;21(5):E559.

5. Kumar S. Medicinal plant resources: Manifestation and prospects of lifesustaining healthcare system. J Biol Sci. 2011;4(1):19-29.

6. Mahdi JG. Medicinal potential of willow: A chemical perspective of aspirin discovery. J Saudi Chem Soc. 2010;14(3):317-22.

7. Hollman A. Drugs for atrial fibrillation: Digoxin comes from Digitalis lanata. $\mathrm{Br}$ Med J. 1996;312(7035):912.

8. Veeresham C. Natural products derived from plants as a source of drugs. J Adv Pharm Technol Res. 2012;3(4):200-1

9. Maridass M, DeBritto AJ. Origins of plant derived medicines. Ethnobot Leaflets. 2008;2008:44.

10. Elkhalifa KF, Ibrahim MA, Elghazali G. A survey of medicinal uses of Gash Delta vegetation, Eastern Sudan. Saudi J Biol Sci. 2006;13(1):1-6.

11. EIGhazali G, EITohami M, EIEgami A. Medicinal plants of the Sudan. Part 3. Medicinal plants of the White Nile provinces. Khartoum: National Centre for Research, Medicinal and aropmatic plants Research Institute. 1994.

12. Godara P, Rao D, Dulara B, Barwar N. Multidimensional approach of endangered ayurvedic plant Leptadenia reticulata: A review. Int J Res Appl Sci Eng. 2015;4(4):531-43.

13. Mohanty SK, Swamy MK, Sinniah UR, Anuradha M. Leptadenia reticulata (Retz.) Wight and Arn.(Jivanti): Botanical, Agronomical, Phytochemical, Pharmacological and Biotechnological Aspects. Molecules. 2017;22(6):E1019.
14. Verma N, Jha K, Chaudhary S, Singh O, Kumar A. Phytochemistry, pharmacology and traditional uses of Leptadenia pyrotechnica-an important medicinal plant. Ind J Pharma Biol Res. 2014;2(1):128.

15. Song Y, Sun H, Zhang A, Yan G, Han Y, Wang X. Plant-derived natural products as leads to anti-cancer drugs. Journal of Medicinal Plant and Herbal Therapy Research. 2014;2:6-15.

16. Iqbal J, Abbasi BA, Mahmood T, Kanwal S, Ali B, Khalil AT. Plant-derived anticancer agents: A green anticancer approach. Asian Pac J Trop Dis. 2017;7(12):1129-50.

17. Parveen M, Malla AM, Ahmad F, Azaz S. Anti-HIV Drug Discovery Struggle: From Natural Products to Drug Prototypes. Natural Products in Clinical Trials. 2018;1:165-232.

18. Yatoo M, Gopalakrishnan A, Saxena A, Parray OR, Tufani NA, Chakraborty $\mathrm{S}$, et al. Anti-inflammatory drugs and herbs with special emphasis on herbal medicines for countering inflammatory diseases and disorders-a review. Recent Pat Inflamm Allergy Drug Discov. 2018;12(1):39-58.

19. Moorthy NSHN, Pratheepa V, Manivannan E. Natural Product Derived Drugs for Immunological and Inflammatory Diseases. Natural Products in Clinical Trials. 2018;(48):31-78.

20. Brindha P. Role of phytochemicals as immunomodulatory agents: A review. Int J Green Pharm. 2016;10(1):1-18.

21. Abood W. Immunomodulatory and Natural Immunomodulators. J Allergy Inflamm. 2017;1:e101.

22. Stephan CE. Methods for calculating an $\mathrm{LC}_{50}$, Aquatic toxicology and hazard evaluation. American Society for Testing and Materials. 1977;634:65-84.

23. Akçay $A$. The calculation of $L_{50}$ using probit analysis. Federation of American Societies for Experimental Biology. 2013;27:lb1-1217.39.

24. Newman DJ, Cragg GM. Natural products as sources of new drugs from 1981 to 2014. J Nat Pdt. 2016;79(3):629-61.

25. Upadhayay UPPDD, Ewam PCVV, Ewam UPCVV, Sansthan GA. Immunomodulatory and Therapeutic Potentials of Herbal, Traditional/ Indigenous and Ethnoveterinary Medicines" Mahima,"Anu Rahal," Rajib Deb, “Shyma K. Latheef," Hari Abdul Samad. Pak J Biol Sci. 2012;15(16):75474.

26. Jantan I, Ahmad W, Bukhari SN. Plant-derived immunomodulators: an insight on their preclinical evaluation and clinical trials. Front Plant Sci. 2015;6:655.

27. Bright JJ. Curcumin and autoimmune disease: The Molecular Targets and Therapeutic Uses of Curcumin in Health and Disease. Advances in Experimental Biology and Medicine: Springer. 2007;425-51.

28. Aggarwal B, Prasad S, Reuter S, Kannappan R, Yadav VR, Park B, et al. Identification of novel anti-inflammatory agents from Ayurvedic medicine for prevention of chronic diseases:"reverse pharmacology" and "bedside to bench" approach. Curr Drug Targets. 2011;12(11):1595-653.

29. Biedermann $T$, Röcken $M$, Carballido $J M$. $\mathrm{TH}_{1}$ and $\mathrm{TH}_{2}$ Lymphocyte Development and Regulation of TH Cell-Mediated Immune Responses of the Skin. J Investig Dermatol Symp Proc. 2004;9(1):5-14.

30. Spellberg B, Edwards JJE. Type 1/Type 2 Immunity in Infectious Diseases. Clin Infect Dis. 2001;32(1):76-102.

31. Saeed TA. Effect of Leptadenia arborea and Syzygium aromaticum on Albino Rats: University of Khartoum. 2006;1-52.

32. Okoye NN, Ajaghaku DL, Okeke HN, Ilodigwe EE, Nworu CS, Okoye FBC. Beta-Amyrin and alpha-amyrin acetate isolated from the stem bark of Alstonia boonei display profound anti-inflammatory activity. Pharma Biol. 2014;52(11):1478-86.

33. Vázquez LH, Palazon J, Navarro-Ocaña A. The Pentacyclic Triterpenes $\alpha$, Bamyrins: A Review of Sources and Biological Activities: Phytochemicals-A global perspective of their role in nutrition and health. In Tech. 2012;487-502.

34. Jansen PCM. Leptadenia hastata (Pers.) Decne: Plant Resources of Tropical Africa 2. Vegetables: PROTA Foundation, Wageningen, Netherlands/ Backhuys Publishers, Leiden, Netherlands. 2004;367-8.

35. Pravansha S, Thippeswamy B, Veerapur V. Immunomodulatory and antioxidant effect of Leptadenia reticulata leaf extract in rodents: possible modulation of cell and humoral immune response. Immunopharmacol Immunotoxicol. 2012;34(6):1010-9.

36. Girishkumar V, Sreepriya M, Praveenkumar S, Bali G, Jagadeesh MS. Modulating effect of Leptadenia reticulata (Retz) Wight and arn against chromate (VI)-induced immunosuppression and oxidative stress on 
mouse splenic lymphocytes and bone marrow derived macrophages. J Ethnopharmacol. 2010;131(2):505-8.

37. Grigore A. Plant Phenolic Compounds as Immunomodulatory Agents: Phenolic Compounds-Biological Activity. In Tech. 2017;75-98.
38. Botham PA. Acute systemic toxicity--prospects for tiered testing strategies. Toxicol in vitro. 2004;18(2):227-30.

39. Acute Oral Toxicity. Organization for Economic Cooperation and Development Guideline for Testing of Chemicals. 1987;401.

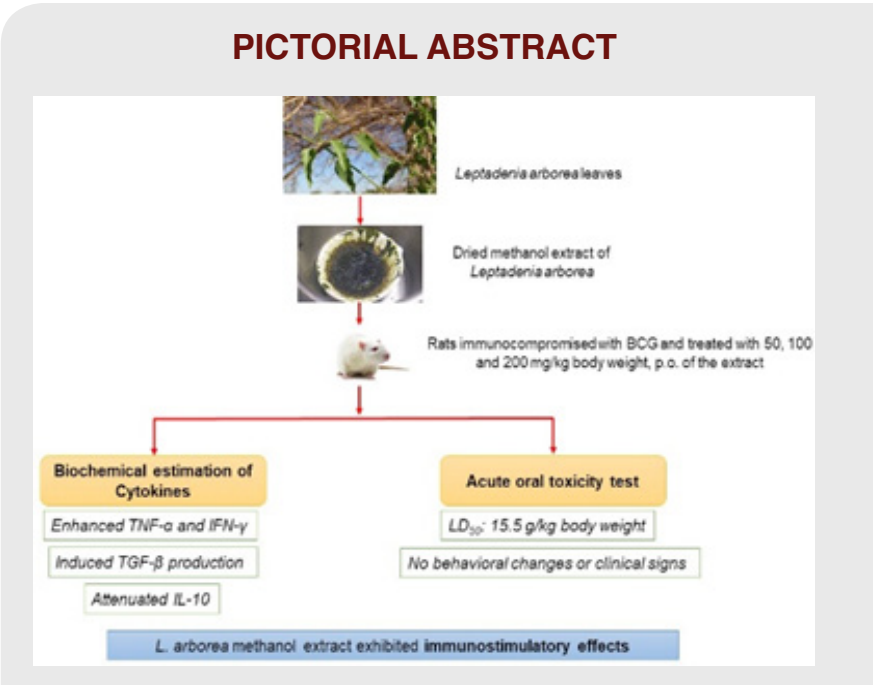

\section{SUMMARY}

- Leptadenia arborea is widely distributed in Sudan and is traditionally used to treat rheumatoid arthritis, gonorrhea, constipation, colic and snake bites.

- Immunomodulatory potential of methanolic extract of $L$. arborea leaves in Bacillus Calmette-Guérin (BCG)-immunized rats was investigated.

- L. arborea extract exhibited a significant dose- and time-dependent increase in the plasma levels of IFN- $\gamma$ and TGF- $\beta$ and decrease in IL-10 levels.

- $\mathrm{LD}_{50}$ value was calculated to be $15.5 \mathrm{~g} / \mathrm{kg}$ body weight and the extract didn't display any behavioral changes or clinical signs after $12 \mathrm{hr}$ of treatment.

\section{About Authors}

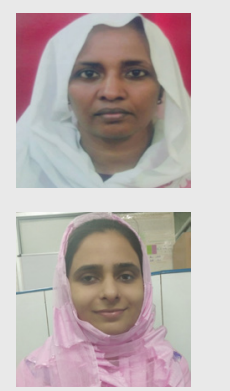

Dr. Iman Hassan Abdoon is Ph.D. In Pharmacology and is currently working as Assistant Professor and Head, Department of Pharmacology, Faculty of Pharmacy, University of Khartoum, Sudan.

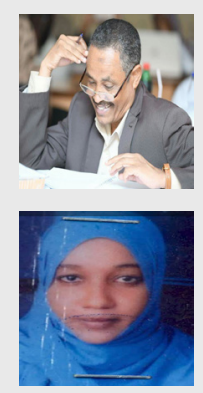

Dr. Bushra Parveen obtained her Ph.D in Pharmaceutical Medicine from Jamia Hamdard, New Delhi, India and is trained in experimental Pharmacology, Clinical Pharmacology, Clinical Biochemistry and Clinical Toxicology.

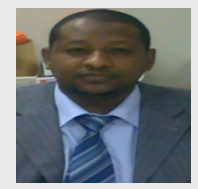

Dr. Bashier Osman is Associate Professor, Department of Pharmacology, Faculty of Pharmacy, University of Khartoum. Currently, he is serving as Dean, Faculty of Pharmacy, University of Khartoum, Sudan.

Dr. Mona S Mohamed is currently the Head Department of Pharmacognosy, Faculty of Pharmacy, University of Khartoum, Sudan.

Dr. Wadah JA Osman is Assistant Professor, Department of Pharmacognosy, Faculty of Pharmacy, University of Khartoum, Sudan. Currently, he is serving as Vice Dean, Faculty of Pharmacy, University of Khartoum, Sudan.

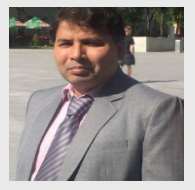

Dr. Sayeed Ahmad is Incharge, Bioactive Natural Laboratory and Associate Professor, Department of Pharmacognosy, School of Pharmaceutical Education and Research, Jamia Hamdard, New Delhi, India.

Cite this article: Abdoon IH, Parveen B, Osman B, Mohamed MS, Osman WJA, Ahmad S. Immunomodulatory potential of Leptadenia arborea in Immune-challenged Rats. Indian J of Pharmaceutical Education and Research. 2020;54(1):101-7. 